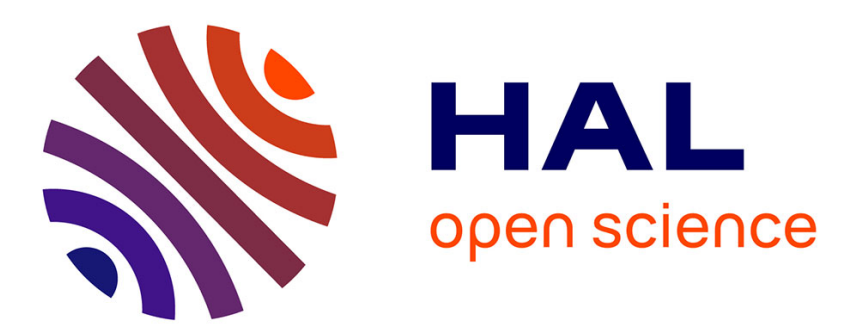

\title{
Isolation and Synthesis of One of the Most Central Cofactors in Metabolism: Coenzyme A
}

\author{
Louis Mouterde, Jon Stewart
}

\section{To cite this version:}

Louis Mouterde, Jon Stewart. Isolation and Synthesis of One of the Most Central Cofactors in Metabolism: Coenzyme A. Organic Process Research and Development, 2018, 23 (1), pp.19-30. 10.1021/acs.oprd.8b00348. hal-02876007

\section{HAL Id: hal-02876007 https://hal.science/hal-02876007}

Submitted on 20 Jun 2020

HAL is a multi-disciplinary open access archive for the deposit and dissemination of scientific research documents, whether they are published or not. The documents may come from teaching and research institutions in France or abroad, or from public or private research centers.
L'archive ouverte pluridisciplinaire HAL, est destinée au dépôt et à la diffusion de documents scientifiques de niveau recherche, publiés ou non, émanant des établissements d'enseignement et de recherche français ou étrangers, des laboratoires publics ou privés. 


\title{
Isolation and Synthesis of One of the Most Central Cofactors in
}

\section{Metabolism: Coenzyme A}

\author{
Louis M. M. Mouterde* and Jon D. Stewart ${ }^{\dagger}$ \\ AgroParisTech, CEBB, 3 rue des Rouges Terres, 51110 Pomacle, France \\ Phone +33.3.52.62.04.65, E-mail louis.mouterde@agroparistech.fr \\ ${ }^{\dagger}$ Department of Chemistry, 126 Sisler Hall, University of Florida, Gainesville, FL 32611 USA \\ *Author to whom correspondence should be addressed
}


Table of Contents Graphic

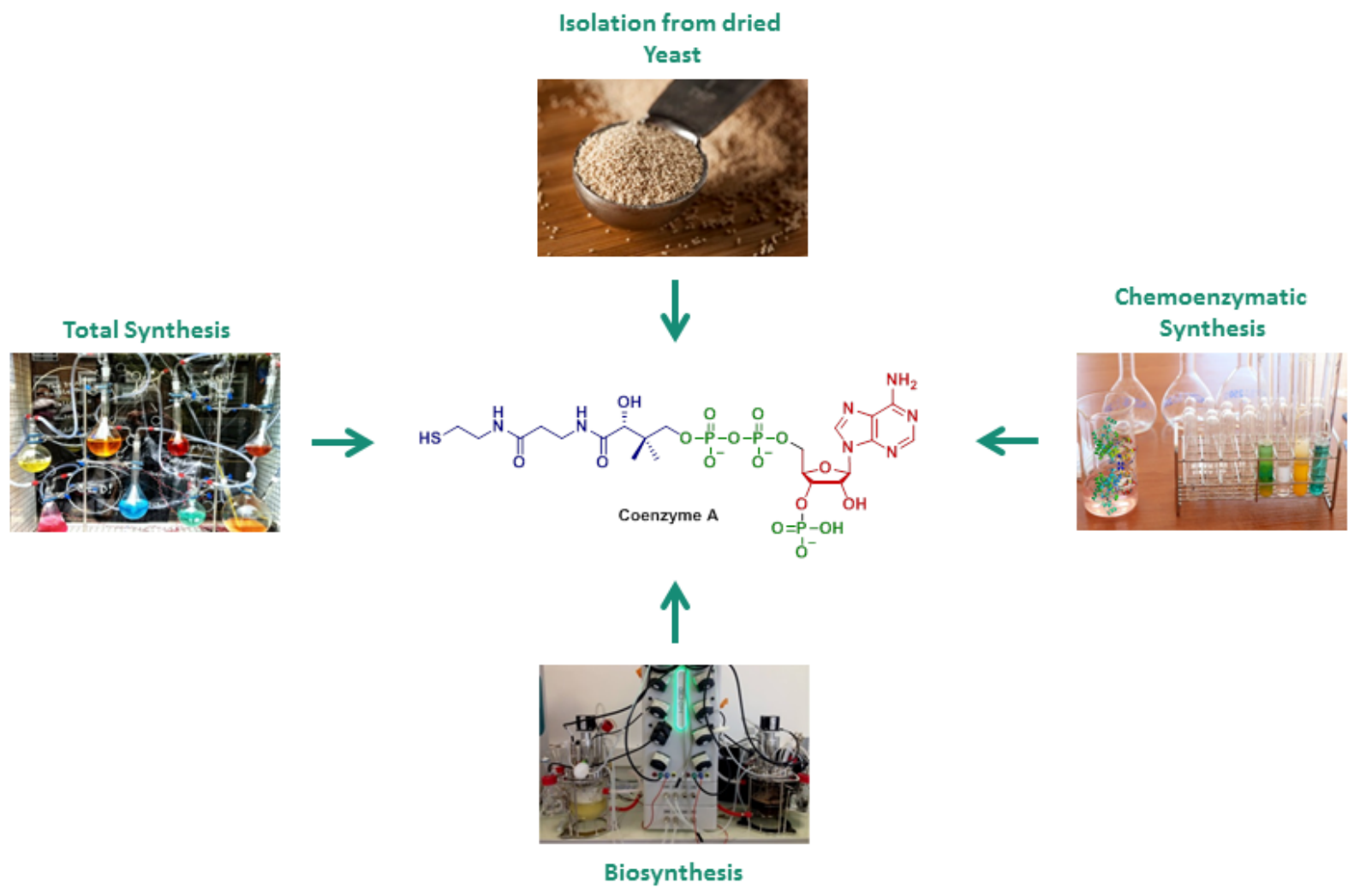




\begin{abstract}
The isolation and synthesis of Coenzyme $\mathrm{A}(\mathrm{CoA})$ has been an important field since this cofactor was discovered in 1947. CoA plays a central role in human metabolism and is vital in several metabolic pathways including fatty acid transport and degradation as well as the biosynthesis of a wide variety of compounds including fatty acids. The high cost of commercially-available CoA ( $\$ 2600 / \mathrm{g}$ with $>85 \%$ purity) has motivated several research groups to find alternatives for its production. The variety of strategies that have been investigated for CoA production can be divided in three categories: isolation from microorganisms, total chemical synthesis and chemoenzymatic synthesis. These approaches provide access to CoA with different efficiencies. For example, direct isolation yields of $\sim 25$ $\mathrm{mg} / \mathrm{kg}$ from dried yeast have been obtained. A variety of microorganisms such as Pseudomonas alkalytica, Sarcina lutea and Brevibacterium ammoniagenes accumulate CoA in their cultures at levels ranging from 0.03 to $115 \mathrm{mg} / \mathrm{mL}$. Total chemical synthesis yields have ranged between 25 and $54 \%$ and chemoenzymatic approaches have provided overall yields of $c a .73 \%$. This review covers all published for producing CoA in order to compare their efficiencies, scalabilities and convenience.
\end{abstract}

Keywords: Coenzyme A, Isolation, Total Synthesis, Chemo-Enzymatic Synthesis. 


\section{Introduction}

The biosynthesis of CoA from vitamin B5 (pantothenic acid 1) is universal in prokaryotes and eukaryotes; however, there was initially some controversy with regard to the actual sequence of steps (Figure 1). Hoagland and Novelli suggested that $\mathbf{1}$ reacts with cysteine to form pantothenoylcysteine 6, which is then decarboxylated to D-pantetheine 7 . Subsequent phosphorylation of the primary alcohol by pantothenate kinase (PanK) was proposed to form phospho-D-pantetheine $\mathbf{4}$ followed by sequential additions of adenosine monophosphate (to form dephospho-CoA 5) and a 3'-phosphate to afford CoA. ${ }^{1}$ Brown et al. challenged this proposal and suggested an alternative route in which phosphorylation of $\mathbf{1}$ occurred first, yielding phosphopantothenate 2. Subsequent condensation and decarboxylation would provide phosphopantothenoylcysteine $\mathbf{3}$, followed by $4 .^{2}$ The final two steps were thought to be the same as those proposed by Hoagland and Novelli (Figure 1).

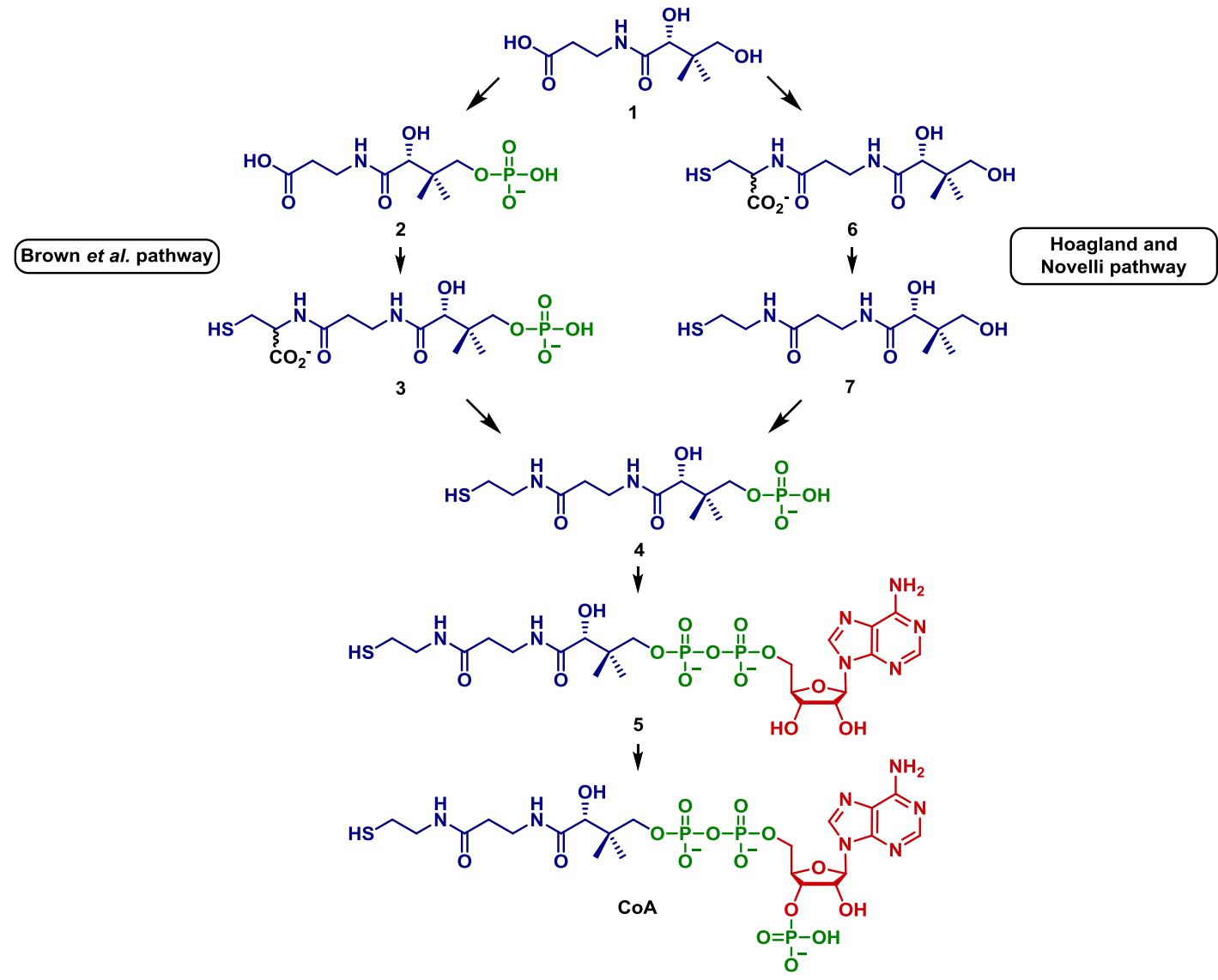

Figure 1. Two possible biosynthetic pathways proposed for CoA. 
To determine the actual biosynthetic route, Abiko investigated substrate selectivity of both PanK and phosphopantothenoylcysteine synthetase (PPCS). By purifying and separating the two enzymes from rat liver, he showed that PPCS did not catalyze the condensation of pantothenate 1 with cysteine in presence of ATP; however, it did accept phosphopantothenate 2. Furthermore, he showed that PanK catalyzed the ATP-dependent phosphorylation of pantothenate 1. These two observations strongly suggested that the first steps of CoA biosynthesis involved the phosphorylation of pantothenate $\mathbf{1}$, followed by a condensation with cysteine to provide $\mathbf{3}$, as initially proposed by Brown et al.

Abiko also made two other observations that greatly influenced later work on CoA synthesis. He noted that PanK - in addition to its normal role in phosphorylating $\mathbf{1}$ - also catalyzed the phosphorylation of both D-pantetheine 7 and $N$-pantothenoyl-cysteine $\mathbf{6}$. This suggested that PanK may also be part of a pathway that recycles intracellular CoA degradation products. This information also offered the possibility for a "shortcut" in synthesizing CoA by using D-pantetheine 7 as a precursor, thereby skipping the enzymecatalyzed steps required to synthesize $7 .^{3}$

Since then, the CoA biosynthetic route proposed by Brown has been generally accepted and all the enzymes involved in the pathway have been characterized. The initial phosphorylation step is catalyzed by PanK. This is followed by condensation with cysteine (using PPCS), then decarboxylation by phosphopantothenoylcysteine decarboxylase (PPCDC). The last two steps are catalyzed by phosphopantetheine adenylyl transferase (PPAT) and dephospho-CoA kinase (DPCK) respectively. These five enzymes are commonly called CoaA, CoaB, CoaC, CoaD and CoaE (Figure 2). 


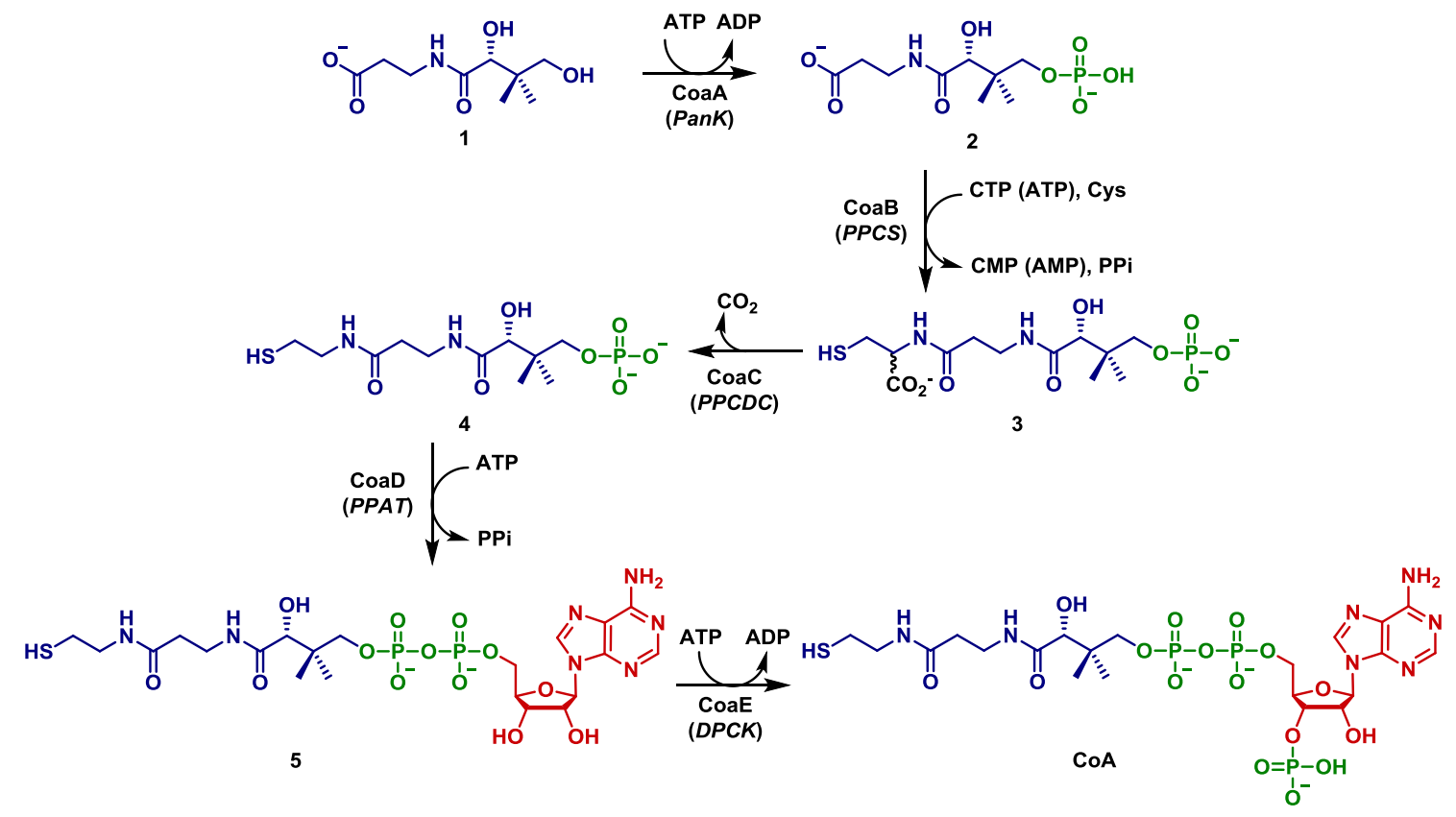

Figure 2. Biosynthesis of Coenzyme A

Many animals, as well as some microbes, cannot synthesize pantothenate, which makes them dependent on the uptake of exogenous vitamin B5. On the other hand, many bacteria (including Escherichia coli) and yeast (including Saccharomyces cerevisiae) can synthesize this precursor. Interestingly, E. coli produces 15 times more pantothenate than required for the biosynthesis of $\mathrm{CoA}^{4}$ Several research teams have taken advantage of this ability to biosynthesize pantothenate 1 for the synthesis of CoA.

Because of its central role in metabolism, CoA has been intensively studied and several reviews have been published to date. These focus on various aspects of CoA chemistry and biology, including its roles specific organisms or CoA analogues and derivatives. Jackowski as well as Strauss focused on CoA biosynthesis and its implication for different metabolic pathways. ${ }^{4} 5$ Saliba assessed the antimicrobial potential of CoA. ${ }^{6}$ With regard to CoA derivatives, two reviews have been published - by Drueckhammer and by Strauss - that describe the production of CoA and its non-natural analogs produced via enzymatic or non-enzymatic strategies. ${ }^{7,} 8$ While previously-published reviews cover important topics with regard to CoA, to the best of our knowledge, no review focused on 
methods to obtains CoA and summarizing the yields and purities obtained has been published to date.

\section{Isolation of Coenzyme A from Microorganisms}

After its discovery in $1947,{ }^{9,10}$ several different strategies to obtain CoA from natural sources have been developed. The first work in this area occurred in the early 1950's when Lipmann et al. and Buyske et al. isolated CoA from animal tissues such as hog liver. ${ }^{11,12}$ While these processes gave access to CoA in some degree of purity, they suffered from poor yields. In parallel, these two teams also showed that CoA could be produced and isolated from microbial sources such as Streptomyces fradiae or yeast. ${ }^{13,14}$ These observations represented an important advance for the study and production of CoA because obtaining the starting materials could be readily obtained (since the microorganisms could be grown easily in short time frames). Buyske et al. improved their process dramatically when they discovered that CoA could be co-precipitated with glutathione in presence of cuprous sulfate. ${ }^{15}$ Using this strategy, they isolated $133 \mathrm{mg}$ of CoA from 6 kilograms of dried yeast with a purity of $c a$. $26 \%$.

In the same year, Stadtman and Kornberg reported a straightforward, two-step purification strategy for CoA from dried yeast. By using charcoal absorption followed by anion exchange chromatography (Dowex $1 \times 2$ ), it was possible to purify $76 \mathrm{mg}$ of CoA from 3 kilograms of dried yeast with a purity of $c a .25 \%$. This method gave a similar yield and purity as the Buyske et al. method, but required fewer purification steps. Unfortunately, the Stadtman and Kornberg method would be difficult to scale up because of massive quantity of anion exchange resin required $(2.3 \mathrm{~kg})$ to provide a relatively small amount of CoA $(75 \mathrm{mg}){ }^{16}$

Crook and coworkers improved the process for isolating CoA from yeast, particularly with regard to purity. After 14 different steps of extraction and purification, they isolated 300 mg of CoA with a purity of approximately $90 \%$. Unfortunately, even this improved procedure 
was still limited by poor yield (30\%) and substantial working volumes (ca. $700 \mathrm{~L}$ of various solvents were used). ${ }^{17}$

\section{Production of Coenzyme A using Engineered Microorganisms}

Nakao et al. discovered that microbial $n$-paraffin assimilators such as Pseudomonas alkanolytica Pd 192, Alcaligenes marshallii Ah 197 and Achromobacter nucleoacidives Ba 108 all accumulated CoA at levels higher than those in organisms that did not assimilate $n$ paraffins. CoA-accumulating organisms yielded around $30 \mu \mathrm{g}$ of CoA per $\mathrm{mL}$ of culture. This allowed them to isolate CoA with a purity of $90 \%$ and yield of $13 \% .{ }^{18}$ A year later, Nishimura reported that Sarcina lutea IAM 1099 accumulated CoA in its reduced form with a concentration of $c a .600 \mu \mathrm{g} / \mathrm{mL}$. They produced CoA in batches of $380 \mathrm{mg}$ with yields over $33 \%$ (based on amounts present in culture broth) and with a purity of $96 \%{ }^{19}$

Shimizu and coworkers published a series of papers from 1970 to 1984 that described the isolation of high purity CoA from a microorganism that was capable of a surprisingly high accumulation capacity. They established that Brevibacterium ammoniagenes IFO 12071 synthesized CoA from pantothenic acid, and that it was possible to reach 3.0 to $5.5 \mathrm{mg} / \mathrm{mL}$ of $\mathrm{CoA}$ in its disulfide form (disulfide $\mathrm{CoA}$ ) in the culture broth. The method used by the authors allowed an extracellularly accumulation of the desired product. ${ }^{20}$ Combining this discovery with a clever purification sequence composed of Duolite S-30 resin, charcoal absorption and anion exchange chromatography (Dowex $1 \times 2$ ), they isolated approximately 1

$\mathrm{g}$ batches of disulfide-CoA with a purity of $c a .80 \%$ from only 1 liter of culture broth. ${ }^{21-23} \mathrm{~A}$ simple reduction by 2 -mercaptoethanol gave $\mathrm{CoA}$ in its reduced form with no loss in activity.

After this initial work, improved methods aimed at reaching an even higher degree of purity were explored. Pantothenic acid, cysteine and ATP were added to dried cells of $B$. ammoniagenes that contained the enzyme cocktail necessary for CoA synthesis. This allowed scaling down the reaction volume from 1,000 to $300 \mathrm{~mL}$ and also reduced the reaction time 
from 6 days to 8 hours. While maximum accumulation levels were somewhat lower than in the fermentation method ( 2 to $3 \mathrm{mg} / \mathrm{mL}$ ), this disadvantage was offset by better recovery $(67 \%)$

The methodology was further improved by using immobilized cells trapped in a polyacrylamide gel to improve enzyme stability. ${ }^{24}$ While this provided lower CoA accumulation levels $(0.5$ to $1.2 \mathrm{mg} / \mathrm{mL})$, the recovery was similar $(65 \%)$ and final product purity was greater $(91 \%)$. It should be noted that both dried cell-based methods gave CoA directly in its reduced form while the first approach provided CoA in its oxidized form. A comparison of the different methods is shown in Table $1 .^{25,26}$

Table 1. Enzymatic activities comparison between different cells sources

\begin{tabular}{cccc}
\hline & Cell fermentation & Dried cells & Immobilized cells \\
\hline Accumulation $(\mathrm{mg} / \mathrm{mL})$ & $3-5$ & $2-3$ & $0.5-1.2$ \\
Form of CoA produced & Oxidized form & Reduced form & Reduced form \\
Purity $(\%)$ & $83-87$ & 85 & 91 \\
Recovery $(\%)$ & 34 & 67 & 65 \\
\hline
\end{tabular}

One drawback of isolating $\mathrm{CoA}$ from $B$. ammoniagenes was that the target accumulated to a maximum level of $5 \mathrm{mg} / \mathrm{mL}$. The authors suspected that PanK might be feedback inhibited by $\operatorname{CoA} .^{27,} 28$ This was overcome by replacing the enzymatic phosphorylation step by chemical phosphorylation. The latter allowed cultures to accumulate CoA at a very high level of $(33 \mathrm{mg} / \mathrm{mL})$, yielding $1.13 \mathrm{~g}$ batches of CoA with a purity of 92\%. A second route using D-pantetheine 7 as the precursor provided even better results (accumulation of $115 \mathrm{mg} / \mathrm{mL}$ in the culture medium and $8 \mathrm{~g}$ of CoA isolated with a purity of $93 \%)^{29}$

A more elegant solution to the feedback inhibition problem was based on a mutant of B. ammoniagenes IFO127071, selected for resistance to oxy-pantetheine, an antimetabolite of D-pantetheine 7. Stewart and Ball established that 4'-oxyphosphopantetheine was converted to the corresponding oxy-analog of CoA (oxy-CoA), which appears to be an inhibitor of 
phosphotransacetylase. ${ }^{30}$ It was therefore proposed that inhibition by oxypantetheine is due to a competition between oxy-CoA and CoA, which causes an up-regulation of CoA production in an attempt to overcome antimetabolite effect. Using the best mutant of B. ammoniagenes IFO127071 from strain improvement mutagenesis, the culture broth gave $9.3 \mathrm{mg}$ of CoA per $\mathrm{mL}$ from pantothenic acid and $11.5 \mathrm{mg}$ of CoA per $\mathrm{mL}$ from D-pantetheine $7 .^{31}$

\section{Chemical Synthesis of Coenzyme A}

Rather than isolating CoA from a microorganism, strategies for synthesizing CoA using both classical chemical methodologies as well as enzyme-assisted strategies have also been explored. For example, CoA can be obtained using a supernatant from disrupted liver cells from several organisms (pigeon, hog or rat) using pantothenic acid $\mathbf{1}$ as precursor. Dephospho-CoA pyrophosphatase (also called dephospho-CoA synthase) and dephosphoCoA kinase are both present in the livers of these preparations and produce CoA from phosphopantetheine. It was also found that pantothenic acid 1 could be converted to Dpantetheine 7 in presence of cysteine using the same liver cell supernatant. Finally, PanK was also detected in these supernatants, which converts D-pantetheine 7 to phospho-pantetheine, the missing link to synthesizing CoA. With the complete biosynthetic route found in the liver preparations, 10.4 Units of CoA were synthesized, which corresponds to $c a$. $7.42 \mu \mathrm{g} .{ }^{1,} 32,33$ This was the first in vitro enzymatic synthesis of CoA reported; unfortunately, the yield of the coenzyme was too low for large scale production.

Several total syntheses of CoA were described in the 1960's. First, Khorana et al., inspired by the work of Baddiley and Thain ${ }^{34}$ reported a convergent 9 step synthetic strategy that started from D-pantolactone $\mathbf{8}$ and adenosine $\mathbf{1 1}$ that yielded CoA with an overall yield of ca. $30 \%$ (Figure 3). ${ }^{35,36}$ The first branch of this scheme involved condensation of $\mathbf{8}$ with $\beta$ alanine 9, followed by a second condensation with $S$-benzylcysteamine which yielded, after global deprotection, phospho-D-pantetheine 4. The second branch of the synthetic strategy 
began with phosphorylation of adenosine 11, followed by formation of the 2',3'-cyclic phosphate 14. Condensation of $\mathbf{4}$ and $\mathbf{1 4}$ under acidic conditions yielded CoA and iso-CoA, the 2'-phosphate isomer of CoA, in $98 \mathrm{mg}$ batches with a purity of $65 \%$.

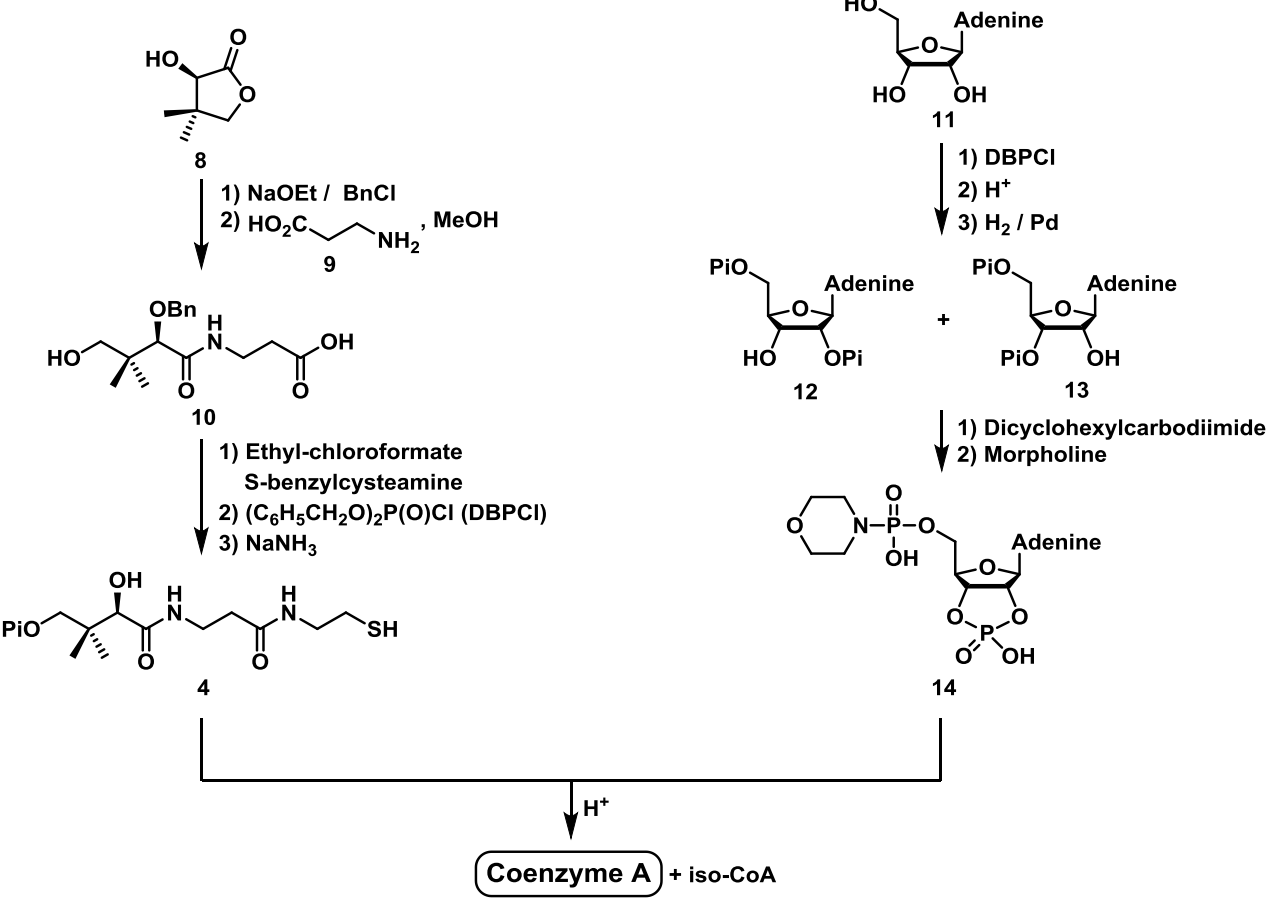

Figure 3. Khorana et al. chemical synthesis of CoA

Gruber et al. also devised a convergent synthetic strategy for synthesizing CoA, using cysteamine 16, $\beta$-alanine 9 and 3'-adenylic acid 20 (isolated from yeast) as precursors (Figure 4). The authors judiciously used orthogonal protecting groups to mask the amine of 9 and the thiol of 16 with benzyl chloroformate $(\mathrm{CbzCl})$ and benzyl chloride $(\mathrm{BnCl})$, respectively. The resulting intermediates, $\mathbf{1 5}$ and $\mathbf{1 7}$, were condensed to yield $\mathbf{1 8}$. Selective deprotection of the amine function of $\mathbf{1 8}$ by sodium in liquid ammonia allowed condensation with 2 '- $O$ methoxymethyl-pantolactone 19. This was followed by deprotection of the thiol by sodium amalgam and its immediate reprotection using benzoyl chloride $(\mathrm{BzCl})$ yielding $\mathbf{2 0}$. Pyrophosphate tetrachloride was condensed with $\mathbf{2 0}$ and the resulting intermediate was reacted with 3'-phosphoadenosine, then hydrolyzed under acidic conditions to give benzoylCoA 22. The final thiol deprotection used sodium hydroxide, providing CoA in 9 steps with a 
purity of $c a .70 \%$ and an overall yield of approximately $25 \% .{ }^{37}$ Unfortunately, the authors noted that they were able to synthesize CoA in only small quantities using this strategy.

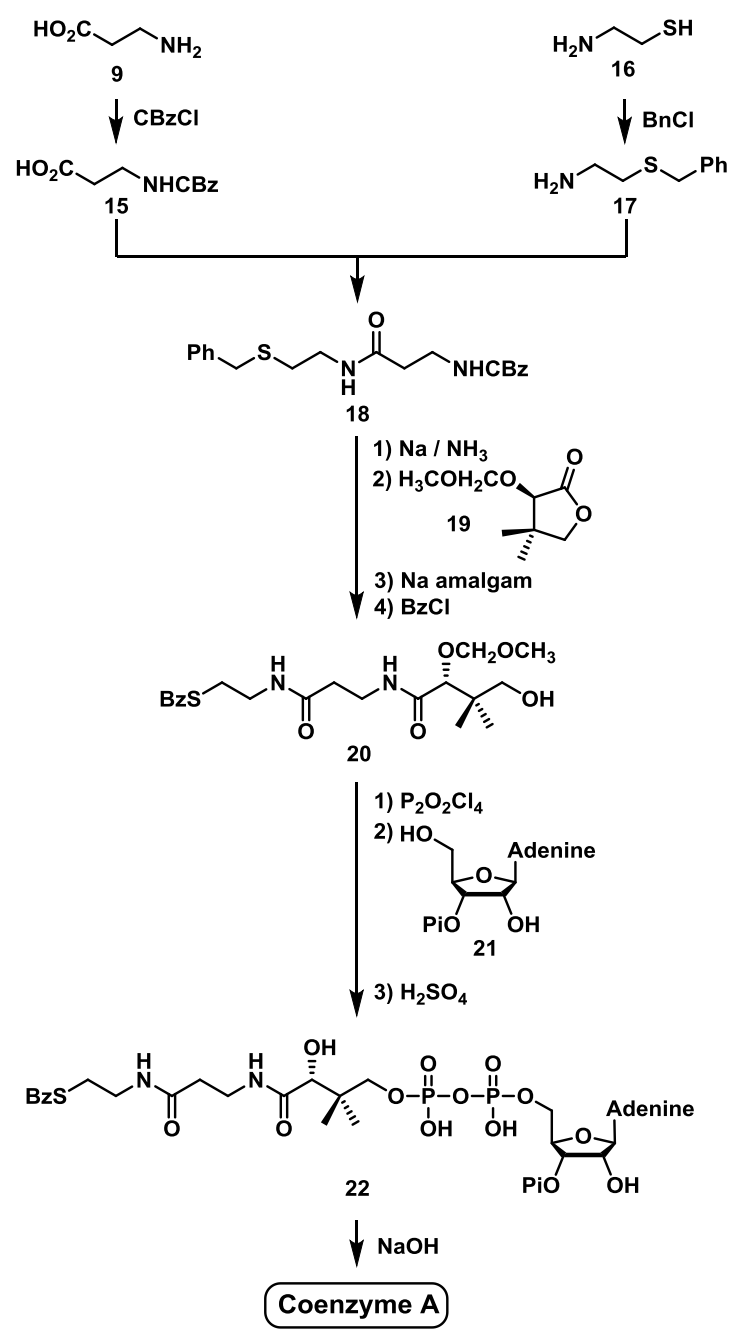

Figure 4. Gruber et al. route to Coenzyme A

Michelson suggested using the disulfide of pantetheine (pantethine) as the precursor for CoA since the disulfide itself would act as a thiol protecting group without introducing extraneous molecular structure. This route used the same methods as Khorana for phosphorylation of 2',3'-cyclic-adenosine $\mathbf{2 3}, 3$ 3',5'-adenosine diphosphates 24 and Dpantethine 46. Condensation of phospho-D-pantethine with 25 yielded 2',3'-cyclic-disulfideCoA 26. Finally, treatment with Ribonuclease $T_{2}$ (RNase $T_{2}$ ), which opened the ring exclusively to adenosine-3'-phosphate, and $\beta$-mercaptoethanol gave access to the final 
product. Michelson prepared batches of $800 \mathrm{mg}$ of CoA with an overall yield of $63 \%$ and a purity of approximately $75 \%$ through a linear 5 step synthetic strategy (Figure 5). ${ }^{38}$

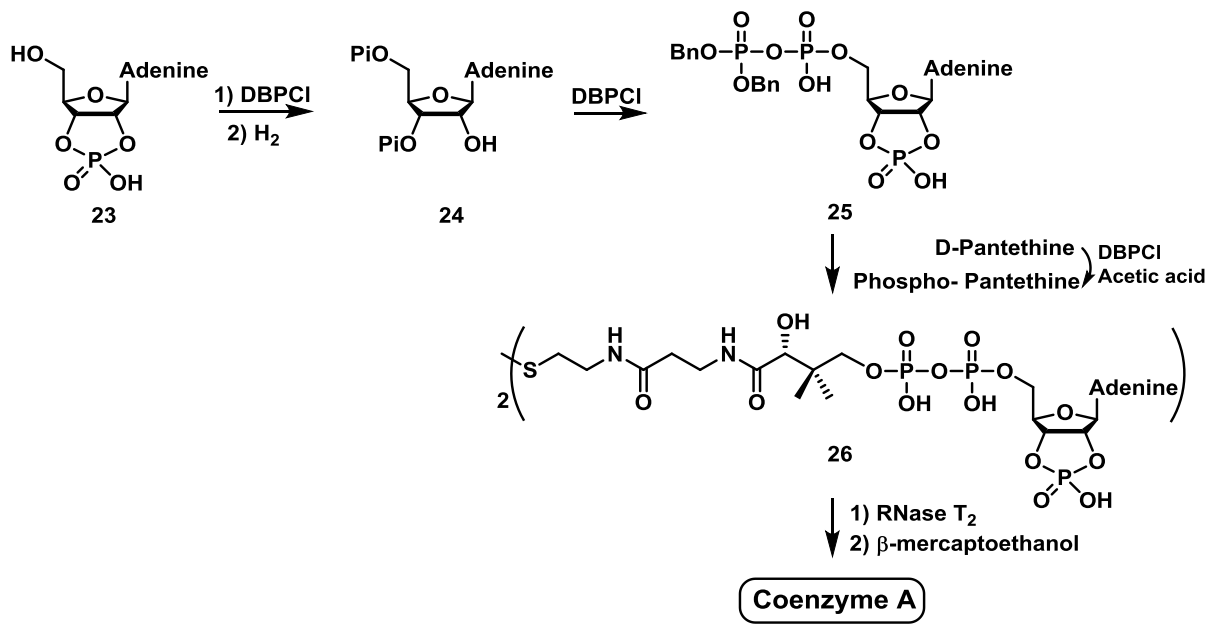

Figure 5. Michelson route to CoA

Shimizu et al. developed a clever synthesis of CoA from D-pantothenonitrile 27 and 2',3'-cyclic phosphate-5'-phosphoromorpholidate $\mathbf{1 4}$, which were condensed in the presence of RNase $\mathrm{T}_{2}$. Subsequent addition of cysteamine $\mathbf{1 6}$ gave thiazoline intermediate $\mathbf{2 8}$. Hydrolysis under acidic conditions gave CoA (Figure 6). This linear 4 step synthetic strategy provided 50 mg batches of the target with an overall yield of approximately $30 \%$ and a purity of $c a$. $80 \% .^{39,40}$

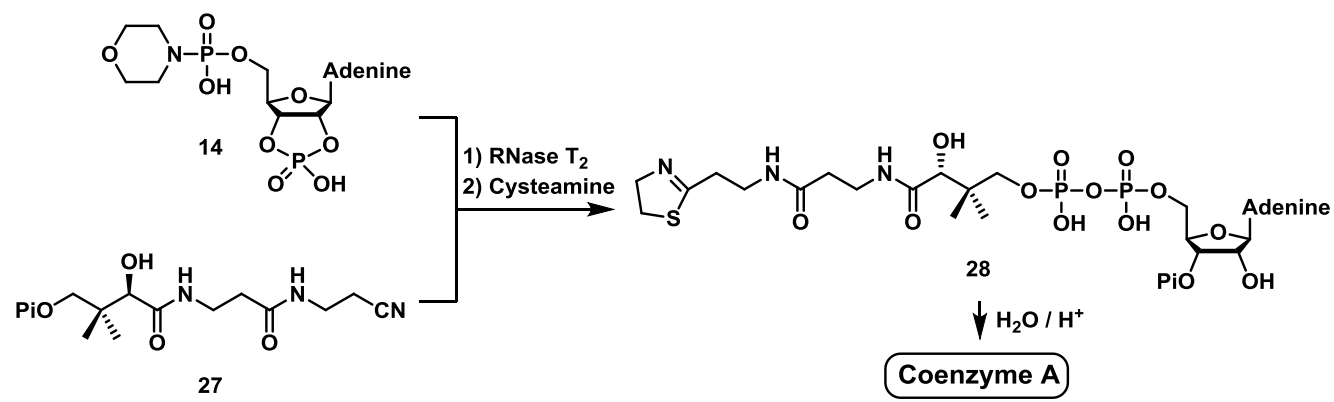

Figure 6. Shimizu route to CoA

Two additional synthetic routes to CoA were described in the 1970's. Mukaiyama and Hashimoto developed an approach that was inspired by the work of Shimizu. This approach combined the synthesis of adenosine 2',3'-cyclicphosphate-5'-phosphoromorpholidate $\mathbf{1 4}$, 
described by Khorana, with the use of RNase $\mathrm{T}_{2}$ to avoid forming iso-CoA (Figure 7). ${ }^{41}$ Phospho-D-pantetheine $\mathbf{4}$ was obtained by condensation of pantothenic acid $\mathbf{1}$ with cystamine, followed by formation of dibenzyl phosphate intermediate 30. This yielded phospho-Dpantetheine 4 when treated sequentially with acetic acid, solid sodium in ammonia and $\beta$ mercaptoethanol. The 9 step synthetic strategy afforded CoA with an overall yield of $36 \%$ and high purity $(98 \%)^{42}$

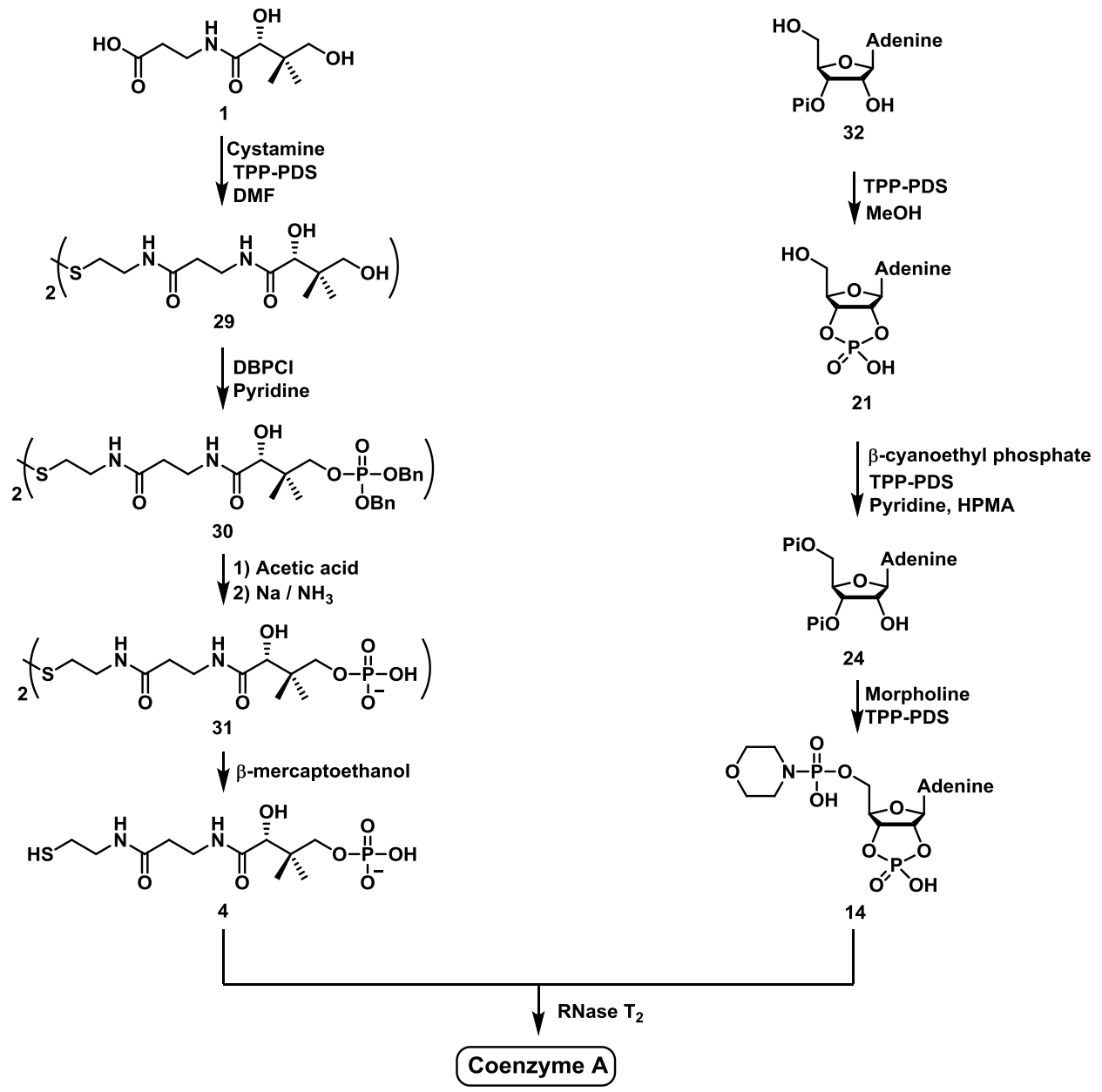

Figure 7. Mukaiyama and Hashimoto synthesis of CoA

A few years later, Mushika et al. published their synthesis of 2',3'-cyclic CoA 35 (oxidized form; Figure 8). The first step of this synthetic strategy involved phosphorylating adenosine 12 using N,N'-dicyclohexylcarbodiimide (DCC) and 2-dimethylamino-4nitrophenyl phosphate 33 . The resulting intermediate $\mathbf{3 4}$ was then condensed with phospho-D- 
pantethine to give 2',3'-cyclic disulfide-CoA 35. They confirmed their target structure by hydrolyzing 35 with $\mathrm{HCl}$ and reducing the disulfide bond with 2-mercaptoethanol; this gave a mixture of CoA and iso-CoA, as expected. This convergent, 3-step synthetic strategy provided high purity 2',3'-cyclic CoA 35 in batches of $770 \mathrm{mg}$ and an overall yield of $54 \%$. Unfortunately, the two hydrolysis products, CoA and iso-CoA, formed an inseparable mixture, which greatly diminished the practical value of this route.. ${ }^{43}$

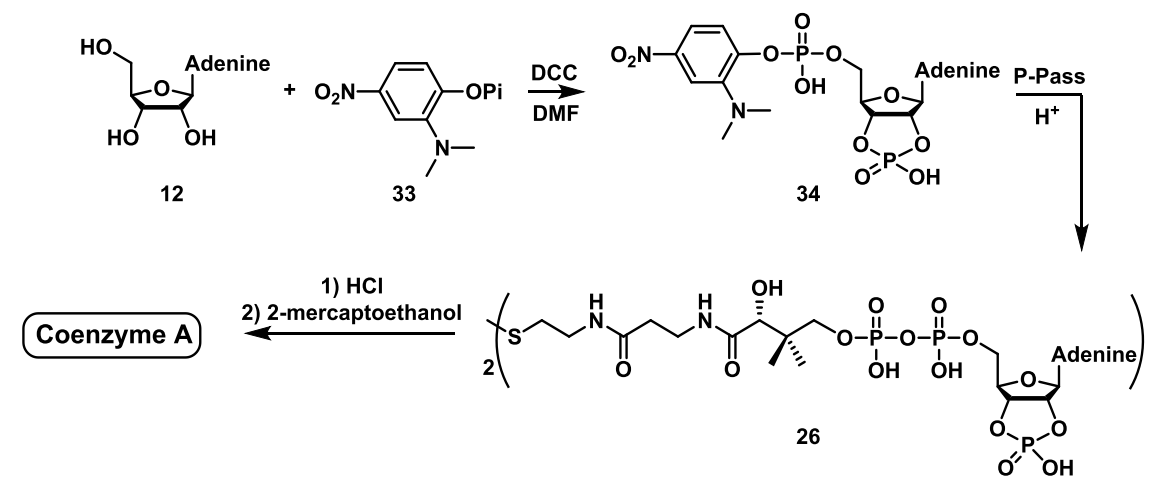

Figure 8. Mushika route to CoA

While majority of the abovementioned syntheses gave CoA at higher degrees of purity than in previous reports, all involved chromatographic purifications of intermediates, relatively complex organic synthesis methods and poor yields that conspired to make scale up difficult.

\section{Chemoenzymatic Synthesis of Coenzyme A}

In addition to isolating CoA from microorganisms or its total chemical synthesis, a third strategy has also been explored: combining chemical synthesis and enzyme-catalyzed steps. Cloning, sequencing and overexpression of the CoA biosynthetic enzymes $\operatorname{PanK}^{44}$, PPAT $^{45}$ and $\mathrm{DPCK}^{46}$ from E. coli facilitated greatly this approach. ${ }^{47-52}$ Strauss, Begley and Ratnam et al. further simplified their production by fusing PanK, PPAT and DPCK with an $N$-terminal hexa-histidine tag for one-step purification after overexpression. ${ }^{53,54}$ The method described by these authors - combined with the earlier discovery of Hoagland and Novelli on substrate promiscuity of PanK - suggested that D-pantetheine 7 might be a viable basis for a 
new chemoenzymatic process for CoA. PPAT and DPCK also tolerated substrate modifications, accepting pendant groups that included thioesters to a tert-butyl ester. It was hypothesized by Stewart et al. that PanK, PPAT and DPCK could all accept substrates with more radical alterations and that D-pantethine $\mathbf{4 6}$ would be an ideal starting material. This would allow the synthesis of CoA in its oxidized form, which would prevent sulfur oxidation, the principal source of CoA degradation. For this reason, synthesis of these two targets has been a priority for all chemoenzymatic routes to $\mathrm{CoA}$.

There are many different routes described in literature that yield D-pantetheine 7 and D-pantethine 46. The first reports were published in the 1950's using different starting materials. The first report of Baddiley and Thain was motivated by needing access to Dpantetheine 7, not only for biological studies but also for synthetic purposes. They therefore developed a convergent synthetic strategy that yielded D-pantetheine 7 with an overall yield of $70 \%$ (Figure 9). Inspired by the work of Sifferd and du Vigneaud, ${ }^{55}$ the first branch of this synthetic strategy employed an activated acyl azide derivative of carbobenzoxy- $\beta$-alanine $\mathbf{3 7}$. Azide 39 was prepared by treating 37 sequentially with $\mathrm{PCl}_{5}$ and hydrazine to give $\mathbf{3 8}$. A final treatment with sodium nitrite under acidic condition yielded azide 39. In the second branch, $S$ benzyl-protected cysteamine was formed by reacting 2-bromoethylamine 35 with benzyl mercaptan 36. The two intermediates formed from the two branches of this approach, $\mathbf{3 6}$ and 39, were coupled to form $\mathbf{4 0}$, which was then treated with ammonia to remove protecting groups from both the thiol and carboxyl ends of $\mathbf{4 0}$, thereby affording aletheine $\mathbf{4 1}$. Condensation with D-pantolactone 8 provided D-pantetheine 7. The authors reported that they were able to produce $3.75 \mathrm{~g}$ batches of pure product $7 .^{56}$ 


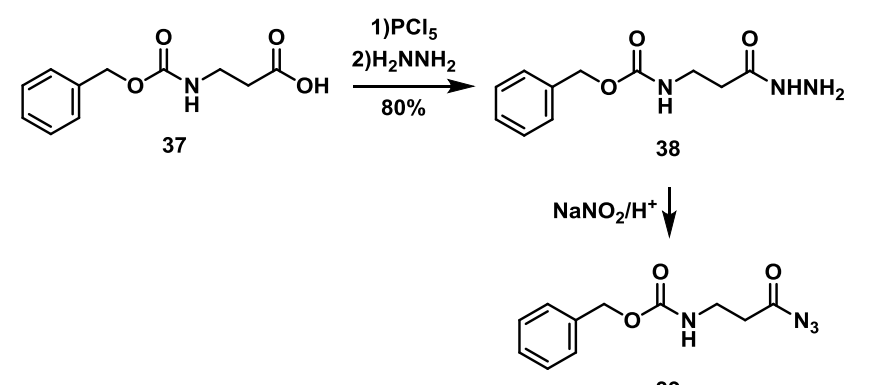

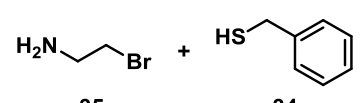

35

34

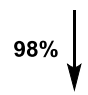

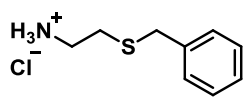

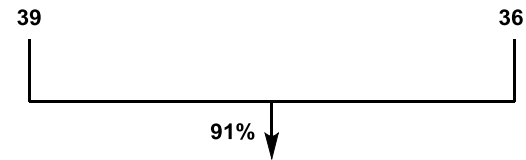<smiles>O=C(CCNC(=O)OCc1ccccc1)NCCSc1ccccc1</smiles>

$\mathrm{Na} / \mathrm{NH}_{3} \downarrow{ } \mathbf{9 9 \%}$<smiles>CCCNC(=O)CCN</smiles>

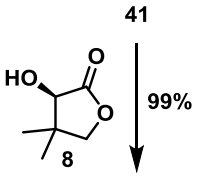<smiles>CC(C)(CO)C(O)C(=O)NCCC(=O)NCCS</smiles>

Figure 9. Baddiley and Thain scheme to D-pantetheine

A few months later, Brown and Snell described a "crossed" synthetic strategy that gave access to both D-pantetheine 7 and D-pantethine 46 (Figure 10). Three strategies were suggested. An "ester process" involved condensing methyl or ethyl pantothenate with cysteamine 16 or cystamine 45, giving D-pantetheine 7 and D-pantethine 46 respectively. An "azide process" was based on the same principle as described above, in which cysteamine $\mathbf{1 6}$ or cystamine $\mathbf{4 5}$ was reacted with pantothenate azide $\mathbf{4 4}$. The latter was obtained by reacting methyl or ethyl pantothenate with hydrazine followed by sodium nitrite under acidic conditions. These two strategies are thus linked to one another and can give either Dpantetheine 7 or D-pantethine 46. The overall yield of the "ester process" was $20-30 \%$ while the "azide process" gave 30-40\% yields. In a third strategy, D-pantolactone $\mathbf{8}$ was condensed with either aletheine 41 or its disulfide analog $\mathbf{4 7}$, which gave results similar to those reported 
by Baddiley and Thain with yields between $80-90 \%$. Using this approach, the authors obtained $200 \mathrm{mg}$ batches of D-pantetheine 7 and $900 \mathrm{mg}$ batches of D-pantethine $\mathbf{4 6}$ by the "Dpantolactone condensation process". 57
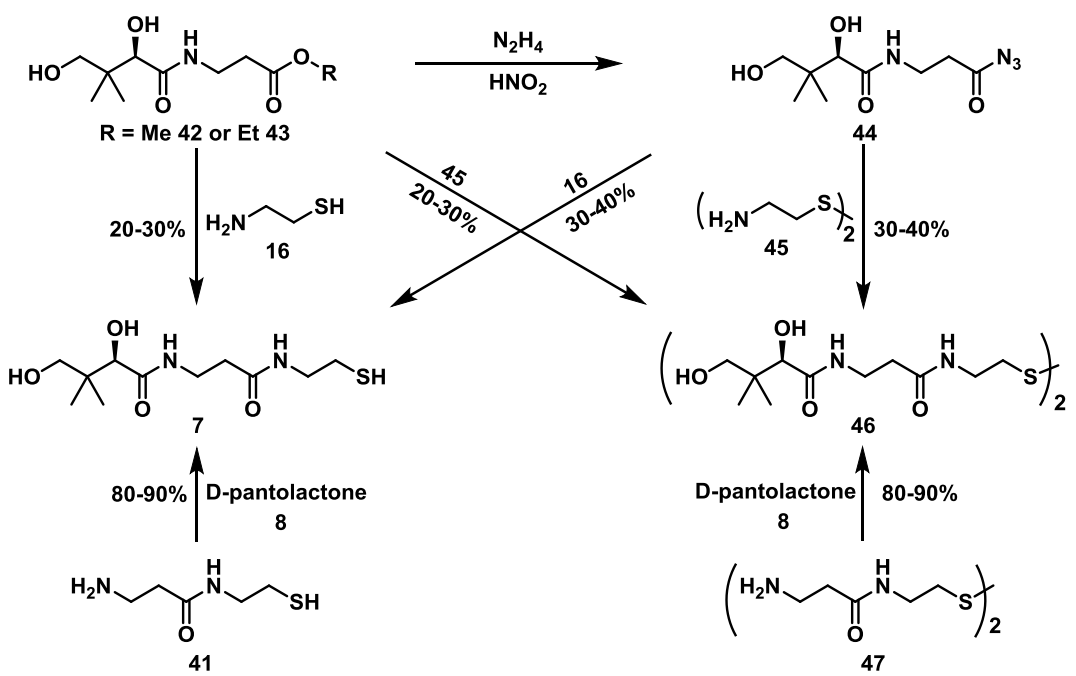

Figure 10. Brown and Snell "crossed" route to D-pantetheine and D-pantethine

In the same year, King et al. reported a linear, 6-step synthetic strategy starting from $\beta$-alanine 9 (Figure 11). After Cbz-protection of the amine moiety, the corresponding acyl chloride was prepared by treatment with thionyl chloride. This was followed by condensation with cystamine $\mathbf{4 5}$ and amine deprotection by sodium in liquid ammonia. The resulting intermediate formed a complex with oxalic acid. The oxalate ion was then trapped by sodium ethoxide in order to liberate the amine for its condensation with D-pantolactone that formed Dpantetheine 7. The overall yield of 7 in $200 \mathrm{mg}$ batches was $23 \% .^{58}$

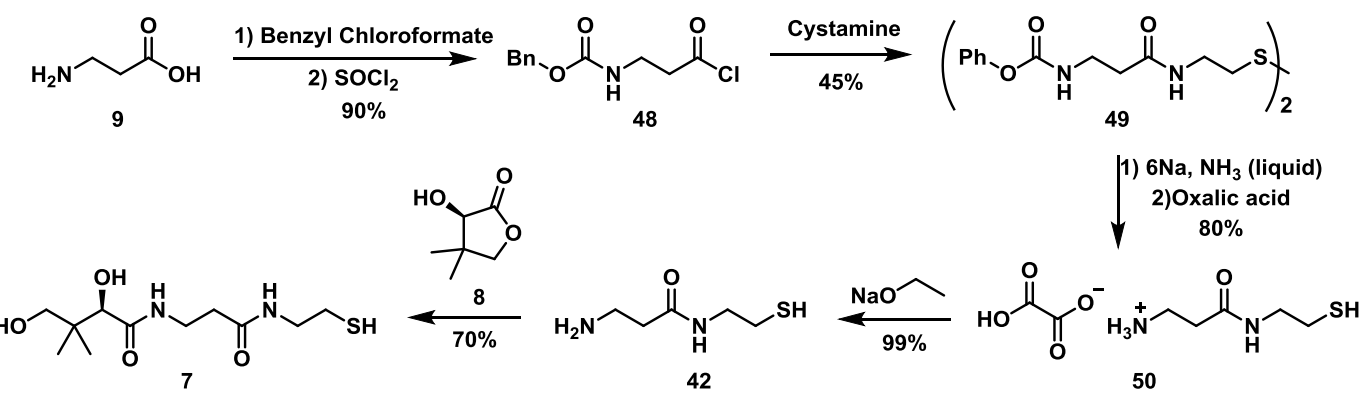

Figure 11. King et al. route to D-pantetheine 
Ten years later, Hosokawa et al. proposed a novel synthesis of the targets using 3aminopropionitrile as starting material (Figure 12). One noteworthy aspect of the authors' approach was that they proposed three different routes in which almost all intermediates are linked to one another. The principal route involved condensing 3-aminopropionitrile 51, $\mathrm{N}$-(2cyanoethyl)-formamide 52 or $N$-(2-cyanoethyl)-acetamide 53 with D-pantolactone 8. The resulting product was then reacted with cysteamine $\mathbf{1 6}$ to yield the corresponding thiazoline ring intermediate 64, which was then hydrolyzed under acidic conditions to give Dpantetheine 7. Conversion to D-pantethine $\mathbf{4 6}$ was done by oxidation using hydrogen peroxide. Using this principal route, the authors accessed both D-pantetheine 7 and D-pantethine 46 in a $70 \%$ overall yield and in $32 \mathrm{~g}$ batches. ${ }^{59}$

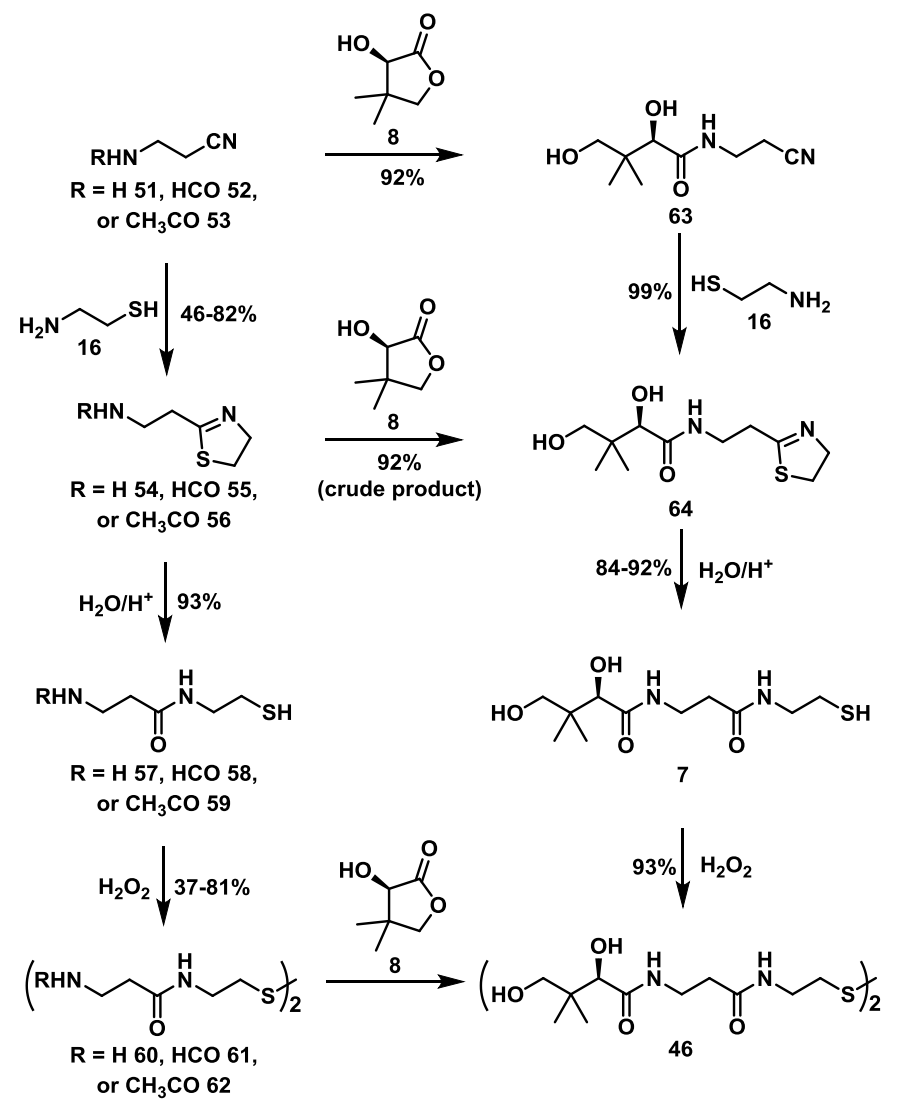

Figure 12. Hosokawa et al. scheme to D-pantetheine and D-pantethine

In 2004, Burkart and coworkers published a new convergent synthetic strategy that yielded D-pantetheine 7 (Figure 13). After reducing D-pantolactone 8 by $\mathrm{LiAlH}_{4}$, two of the 
hydroxyls of triol 69 were protected as an acetal using $p$-(dimethoxy-methyl)-anisole in the presence of camphorsulfonic acid. This was followed by Swern oxidation of remaining hydroxyl and a subsequent mild chlorite (Pinnick) oxidation to yield the corresponding carboxylic acid 71. In the other branch of the synthetic strategy, the authors protected the amine function of cysteamine $\mathbf{1 6}$ with triphenylmethyl chloride, then condensed $\mathbf{6 5}$ with Fmoc- $\beta$-alanine $\mathbf{6 6}$ to form amide 67, from which the Fmoc group was cleaved by piperidine. The two key intermediates (68 and 71) were joined by an EDCI coupling to yield 72. Global deprotection by iodine yielded D-pantetheine 7, which was produced in $5 \mathrm{mg}$ batches and with an overall yield of $25 \% .^{60,61}$

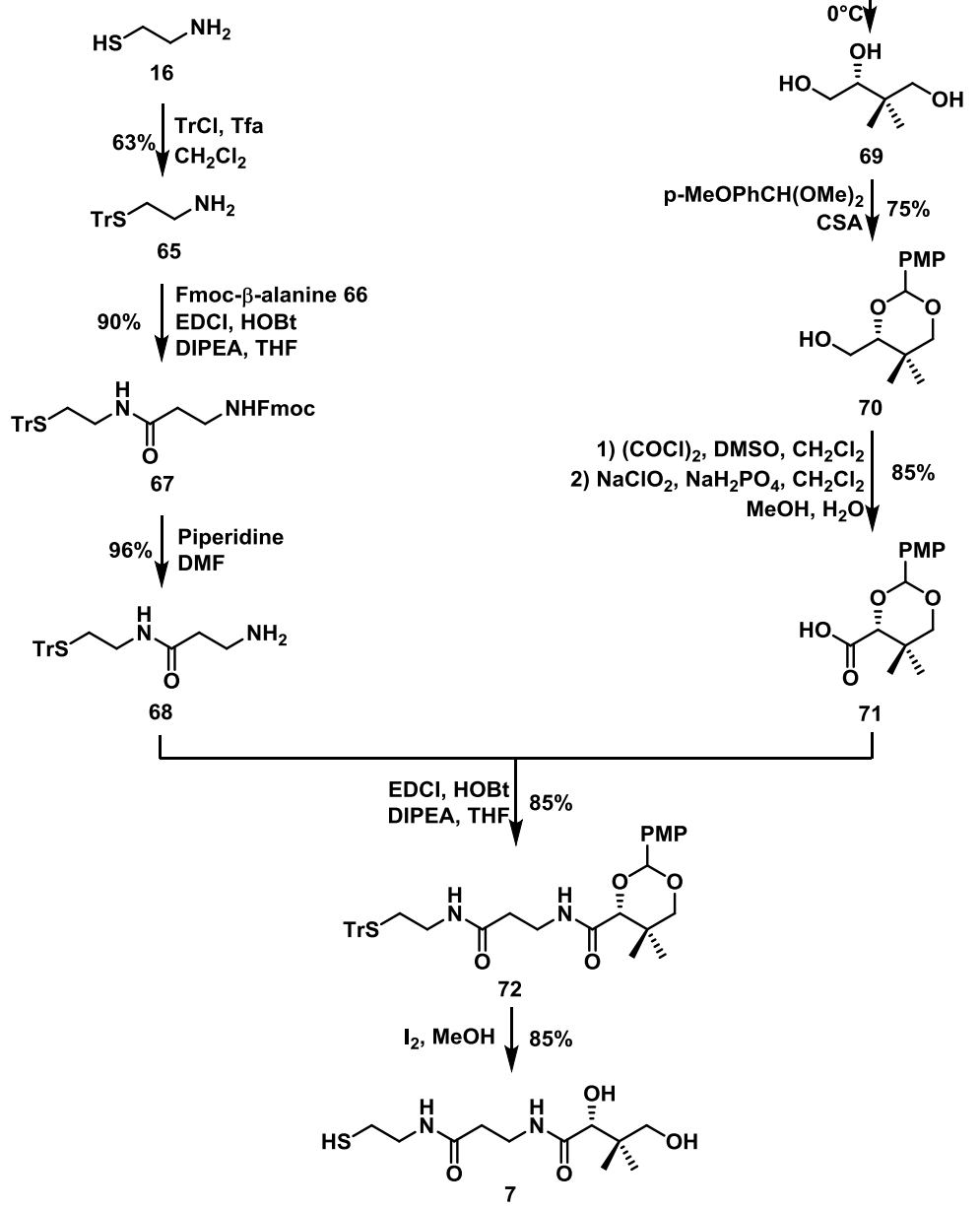

Figure 13. Burkart et al. scheme to D-pantetheine 
One year later, the Burkart group proposed an alternative pathway to D-pantetheine 7 in a publication mainly concerned with carrier protein labeling (Figure 14). Using pantothenic acid 1 as the starting material, the authors employed the same acetal protecting and EDCI coupling strategies to form $\mathbf{7 3}$. This was condensed with cysteamine $\mathbf{1 6}$ and deprotected with $\mathrm{HCl}$ to yield D-pantetheine $\mathbf{7}$ as well as its analogues in a linear, 4-step route. Unfortunately, no yields or batch sizes were indicated for this route. ${ }^{62}$

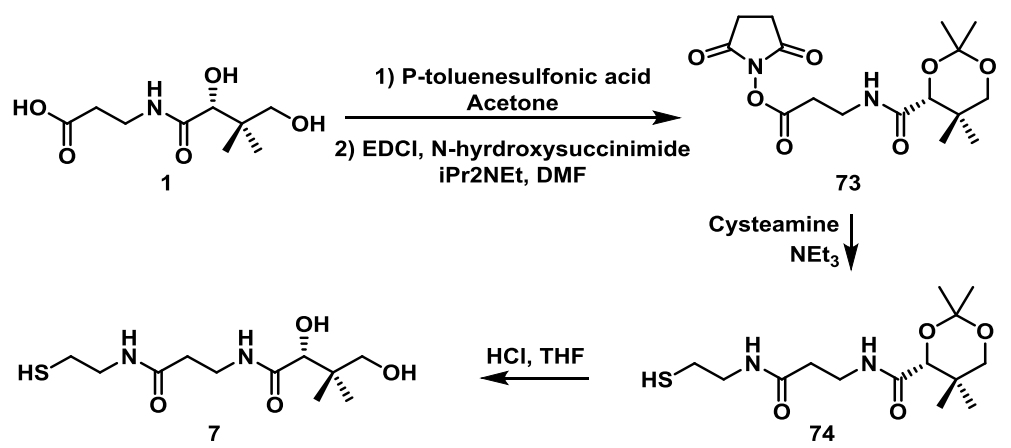

Figure 14. Burkart's alternative route to D-pantetheine

Another route to D-pantetheine 7 was described by Kandula in 2014 (Figure 15). The first 5 steps of this synthetic strategy were based on earlier the work of Marquez et al., who focused on the synthesis of pantothenic acid $1 .{ }^{63}$ After opening D-pantolactone 8 with liquid ammonia and using the same acetal protecting strategy as described by Burkart, the resulting amide intermediate 76 was reacted with $1 H$-benzotriazole-1-carbaldehyde and $n$-butyl-lithium to give the corresponding formamide 77. This was followed by a Wittig reaction and alkene hydrogenation in the presence of $\mathrm{Pd} / \mathrm{C}$. A second amide bond was formed with cysteamine $\mathbf{1 6}$ in the presence of HATU and triethylamine and this was followed by acetal deprotection using $\mathrm{BiCl}_{3}$ to give the final product. Unfortunately, the overall yield of this process remains unknown because data were only reported for only three of the seven steps. However Kandula did report that $800 \mathrm{mg}$ batches of D-pantetheine 7 were produced. ${ }^{64}$ 


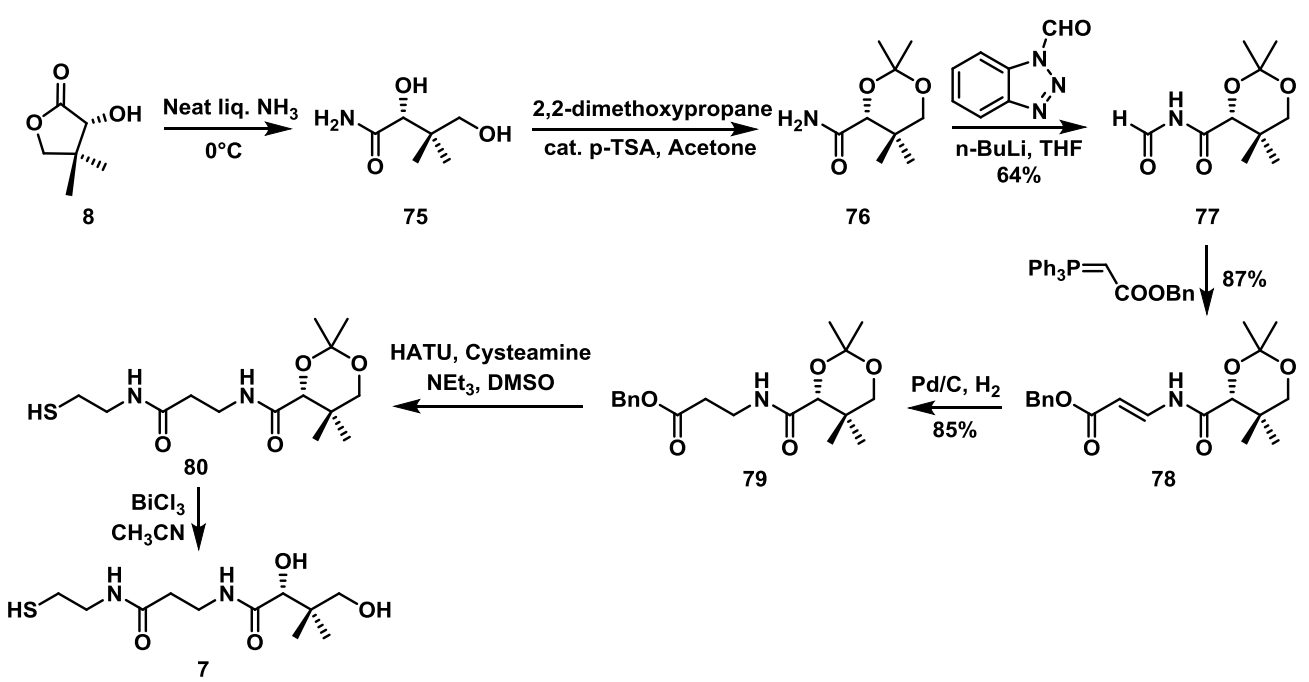

Figure 15. Kandula scheme to D-pantetheine

The last synthesis of D-pantetheine $\mathbf{7}$ and D-pantethine $\mathbf{4 6}$ reported in the literature was described by Stewart et al. in 2016 (Figure 16). This linear synthetic strategy involved the initial Boc protection of $\beta$-alanine 9 to yield 81, which was condensed with cystamine using EDCI and HOBt to yield Boc-alethine 82. As in previous approaches, the disulfide derivative acted both as a protecting group for the nucleophilic thiol as well as preventing undesired sulfur oxidation. After Boc deprotection using trifluoroacetic acid, alethine $\mathbf{8 3}$ was reacted with D-pantolactone 8 yielding D-pantethine 46. Reduction of the disulfide bond using TCEP gave access to D-pantetheine 7. Using this linear synthetic strategy, Stewart et al. accessed both D-pantetheine 7 and D-pantethine 46 in a 76\% overall yield and in $5 \mathrm{~g}$ batches. The authors also reported that this route did not require any chromatographic purification steps, which facilitated greatly scale up of this method. ${ }^{65}$

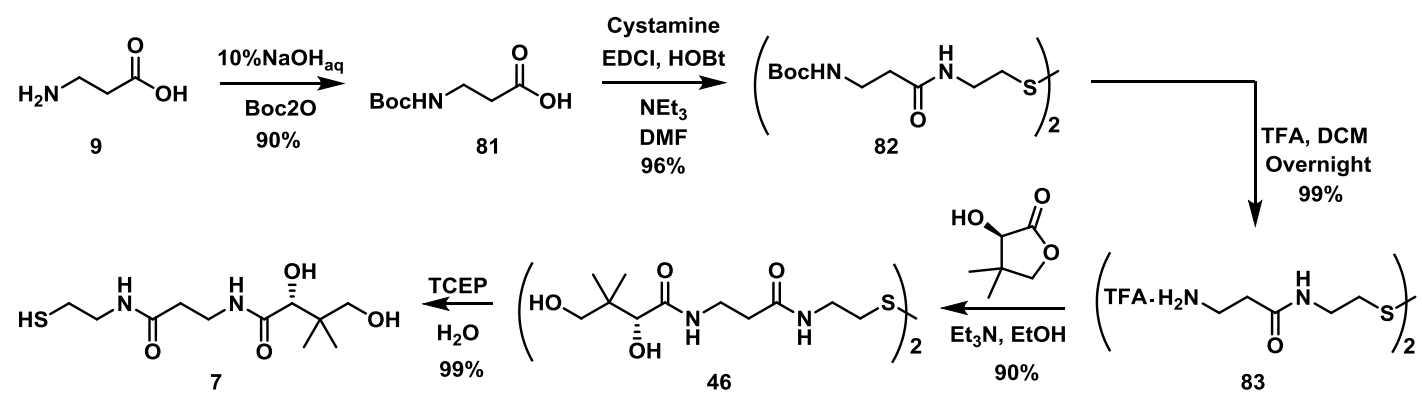

Figure 16. Stewart et al. scheme to D-pantethine and D-pantetheine 
While all of these synthetic strategies yielded D-pantetheine 7 and/or D-pantethine $\mathbf{4 6}$, they differed in regard to yield, scalability some contain one or more synthetically challenging steps. Three principal reagents that are common to nearly all synthetic strategies are Dpantolactone 8, cysteamine 16 and $\beta$-alanine 9 (or their analogues). All data that were published for these different routes are summarized in Table 2.

Table 2. Summary of the different syntheses of D-pantetheine $\mathbf{7}$ and D-pantethine $\mathbf{4 6}$

\begin{tabular}{cccc}
\hline Method & Overall yield & Batch quantity & Chromatography required \\
\hline Baddiley and Thain & $70 \%$ & $3.75 \mathrm{~g}$ & Yes \\
Brown and Snell & $c a .85 \%$ & $200-900 \mathrm{mg}$ & Yes \\
King et al. & $23 \%$ & $200 \mathrm{mg}$ & Yes \\
Hosokawa et al. & $70 \%$ & $32 \mathrm{~g}$ & Yes \\
Burkart et al. (2004) & $25 \%$ & $5 \mathrm{mg}$ & Yes \\
Burkart et al. (2005) & $\mathrm{N} / \mathrm{A}$ & $\mathrm{N} / \mathrm{A}$ & Yes \\
Kandula & $47 \%$ & $800 \mathrm{mg}$ & Yes \\
Stewart and Mouterde & $76 \%$ & $5.04 \mathrm{~g}$ & No \\
\hline
\end{tabular}

Stewart et al. combined their synthetic method for D-pantetheine 7 and D-pantethine 46 with the observations made by $\mathrm{Abiko}^{3}$ to develop a chemoenzymatic pathway to CoA. The catalytic enzymes activities of the three purified enzymes (PanK, PPAT and DPCK) were first verified using their natural substrate (D-pantetheine 7). To overcome the issue of product inhibition, a sequential enzyme addition strategy was chosen, rather than a one-pot approach. Each enzymatic step proceeded with essentially complete conversion according to HPLC. Because these enzymes also accepted pantetheine analogs, the same sequence of enzymatic steps were applied to the disulfide derivative, pantethine 46. These reactions were equally successful, and both ends of the dimer reacted completely. This conversion was carried out on a gram scale (using up to $720 \mathrm{mg}$ of D-pantethine 46) to yield $1.89 \mathrm{~g}$ of disulfide-CoA. The disulfide could be easily reduced with TCEP to yield free CoA with an $82 \%$ purity. The overall yield from $\beta$-alanine was $73 \%$ (Figure 17). ${ }^{65}$ It should also be noted that this strategy was also used by Moore et al. in order to access acyl-CoAs. ${ }^{66}$. The much greater chemical 
stability of disulfide CoA and its precursors is a key advantage, allowing storage indefinitely at room temperature in the presence of oxygen.

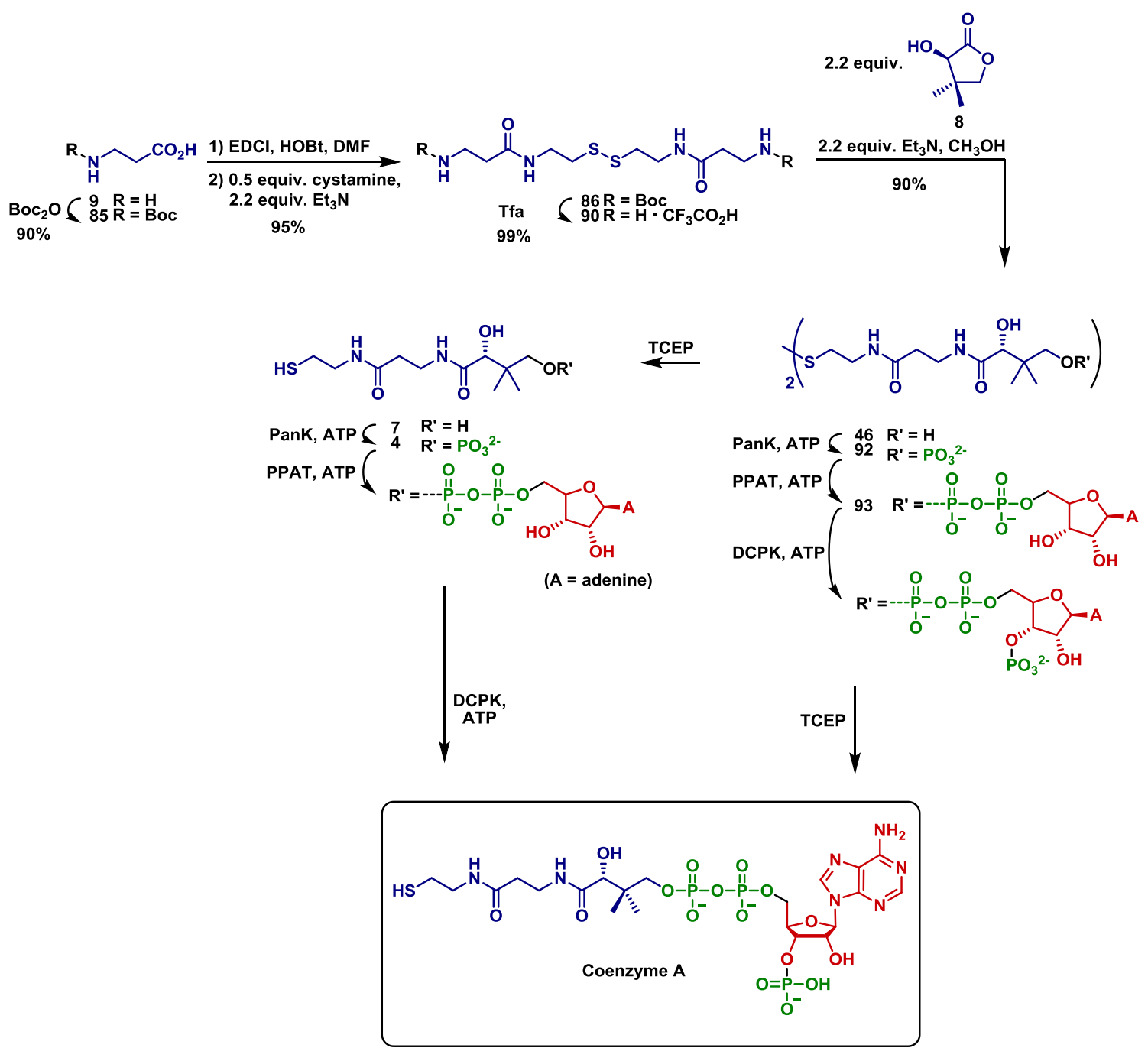

Figure 17. Stewart et al. chemoenzymatic scheme to CoA and its disulfide

\section{Conclusion}

Coenzyme A is an essential acyl carrier and co-factor for many biochemical processes. In addition to selectivity for the acyl moiety of CoA derivatives, enzymes also commonly interact with the cofactor portion and generally have little tolerance for structural perturbations. Because the CoA moiety is covalently joined, this cofactor is required in stoichiometric quantities. On small scales, e.g., in biochemical assays, this is not a serious 
problem; however, if acyl-CoA-requiring enzymes are to be used for preparative synthesis, the high cost of commercial CoA ( $\$ 2600 / \mathrm{g}$ with $>85 \%$ purity) becomes prohibitive.

Therefore, convenient, large-scale access to CoA has been the goal for numerous research teams over the past 70 years. A variety of methods have been described for CoA production, ranging from fermentation to total synthesis (including chemoenzymatic synthesis). This review has collected all methods known to be published to date, and these are summarized below in Table 3 .

Table 3. Summary of the different pathways yielding to CoA

\begin{tabular}{|c|c|c|c|c|}
\hline Author(s) & Method & Concentration & Yield (\%) & Purity (\%) \\
\hline Buyske et al. & Isolation & $22 \mathrm{mg} / \mathrm{kg}$ & - & 26 \\
\hline Stadtman and Kornberg & Isolation & $25 \mathrm{mg} / \mathrm{kg}$ & - & 25 \\
\hline Crook et al. & Isolation & $12 \mathrm{mg} / \mathrm{kg}$ & 30 & 90 \\
\hline Nakao et al. & Isolation & $30 \mu \mathrm{g} / \mathrm{mL}$ & 13 & 90 \\
\hline Nishimura et al. & Isolation & $600 \mu \mathrm{g} / \mathrm{mL}$ & 33 & 96 \\
\hline Shimizu et al. (1973) & Isolation & $3-5.5 \mathrm{mg} / \mathrm{mL}$ & 34 & 80 \\
\hline Shimizu et al. (1974) & Isolation & $2-3 \mathrm{mg} / \mathrm{mL}$ & 67 & 85 \\
\hline Shimizu et al. (1979) & Isolation & $0.5-1.2 \mathrm{mg} / \mathrm{mL}$ & 65 & 91 \\
\hline Shimizu et al. (1983) & Isolation & $115 \mathrm{mg} / \mathrm{mL}$ & 68 & 93 \\
\hline Shimizu et al. (1984) & Isolation & $11.5 \mathrm{mg} / \mathrm{mL}$ & 65 & 91 \\
\hline Khorana et al. & Total synthesis & - & 30 & 65 \\
\hline Gruber et al. & Total synthesis & - & 25 & 70 \\
\hline Michelson & Total synthesis & - & 63 & 75 \\
\hline Shimizu et al. (1965) & Total synthesis & - & 30 & 80 \\
\hline Mukaiyama et al. & Total synthesis & - & 36 & 98 \\
\hline Mushika et al. & Total synthesis & - & 54 & - \\
\hline Stewart et al. & Chemoenzymatic & $19 \mathrm{mg} / \mathrm{mL}$ & 76 & 82 \\
\hline
\end{tabular}

\section{Acknowledgments}

This work was partially supported by the National Science Foundation (CHE1111791). 


\section{References}

1. Hoagland, M. B.; David Novelli, G., Biosynthesis of Coenzyme A from Phosphopantetheine and of Pantetheine from Pantothenate. J. Biol. Chem. 1954, 207, $767-$ 773.

2. Brown, G. M., The Metabolism of Pantothenic Acid. J. Biol. Chem. 1958, 234, 370378.

3. Abiko, Y., Investigations on Pantothenic Acid and its Related Compounds. J. Biochem. 1967, 61, 290-299.

4. Leonardi, R.; Zhang, Y.-M.; Rock, C. O.; Jackowski, S., Coenzyme A: Back in Action. Prog. Lipid Res. 2005, 44, 125-153.

5. Strauss, E., Coenzyme A Biosynthesis and Enzymology. In Comprehensive of Natural Products II: Chemistry and Biology, Elsevier, Ed.2010; pp 351-410.

6. Spry, C.; Kirk, K.; Saliba, K. J., Coenzyme A Biosynthesis: an Antimicrobial Drug Target. FEMS Microbiol. Rev. 2008, 32, 56-106.

7. Strauss, E.; de Villiers, M.; Rootman, I., Biocatalytic Production of Coenzymes A Analogues ChemCatChem 2010, 2, 929-937.

8. Mishra, P. K.; Drueckhammer, D. G., Coenzyme A Analogues and Derivatives: Synthesis and Applications as Mechanistic Probes of Coenzyme A Ester-Utilizing Enzymes Chem. Rev. 2000, 100, 3283-3309.

9. Lipmann, F.; Kaplan, N. O.; Novelli, G. D.; Tuttle, C. L.; Guirard, B. M., Coenzyme for Acetylation, a Pantothenic Acid Derivative. J. Biol. Chem. 1947, 167, 869-870.

10. Kaplan, N. O.; Lipmann, F., The Assay and Distribution of Coenzyme A. J. Biol. Chem. 1948, 174, 37-44.

11. Lipmann, F.; Kaplan, N. O.; Novelli, G. D.; Tuttle, C. L., Isolation of Coenzyme A. J. Biol. Chem. 1950, 186, 235-242.

12. Buyske, D. M.; Handschumacher, R. E.; Higgins, H.; King, T. E.; Strong, F. M.; Cheldelin, V. H.; Teply, L. J.; Mueller, G. C., Preparation and Purification of Coenzyme A Concentrates. J. Biol. Chem. 1951, 193, 307-316.

13. DeVries, W. H.; Grover, W. M.; Evans, J. S.; Gregory, J. D.; Novelli, G. D.; Soodak, M.; Lipmann, F., Purification of Coenzyme A from Fermentation Sources and its further Partial Identification. J. Am. Chem. Soc. 1950, 72, 4838.

14. Beinert, H.; Von Korff, R. W.; Green, D. E.; Buyske, D. A.; Handschumacher, R. E.; Higgins, H.; Strong, F. M., A Method for Purification of Coenzyme A. J. Am. Chem. Soc. 1951, 74, 854-855.

15. Beinert, H.; Von Korff, R. W.; Green, D. E.; Buyske, D. A.; Handschumacher, R. E.; Higgins, H.; Strong, F. M., A Method for the Purification of Coenzyme A from Yeast. J. Biol. Chem. 1953, 200, 385-400.

16. Stadtman, E. R.; Kornberg, A., The Purification of Coenzyme A by Ion Exchange Chromatography. J. Biol. Chem. 1953, 203, 47-54.

17. Reece, M. C.; Donald, M. B.; Crook, E. M., The Evaluation of a Process for the Preparation of Coenzyme A from Yeast. J. Biochem. Microbiol. Technol. Eng. 1959, 1, 217228.

18. Kuno, M.; Kikuchi, M.; Nakao, Y., Production of Coenzyme A by $n$-Paraffinsassimilating Microorganisms. Agric. Biol. Chem. 1973, 37, 313-319.

19. Nishimura, N.; Shibatani, T.; Kakimoto, T.; Chibata, I., Production of Coenzyme A by Sarcina lutea. Appl. Microbiol. 1974, 28, 117-123.

20. Shimizu, S.; Mityata, K.; Tani, Y.; Ogata, K., An Improved Method for the Fermentative Production of Coenzyme A from Pantothenic Acid, Cysteine, and 5'-AMP. Agric. Biol.Chem. 1973, 37, 607-613. 
21. Ogata, K.; Shimizu, M.; Tani, Y., A New Preparation Method of Coenzyme A. Agric. Biol. Chem. 1970, 34, 1757-1759.

22. Shimizu, M.; Miyata, K.; Tani, Y.; Ogata, K., A New Process for the Production of Coenzyme A and its Intermediates with a Microorganism. Biochim. Biophys. Acta 1972, 279, 583-586.

23. Shimizu, S.; Miyata, K.; Tani, Y.; Ogata, K., A New Process for the Production of Coenzyme A. Agric. Biol. Chem. 1973, 37, 615-619.

24. Chibata, I.; Tosa, T.; Sato, T., Immobilized Aspartase-Containing Microbial Cells: Preparation and Enzymatic Properties. Appl. Microbiol. 1974, 27, 878.

25. Shimizu, S.; Tani, Y.; Ogata, K., Synthesis of Coenzyme A and Its Biosynthetic Intermediates by Microbial Processes. Meth. in Enzymol. 1979, 62, 236-245.

26. Shimizu, M.; Tani, Y.; Hideaki, Y., Synthesis of Coenzyme A by Immobilized Bacterial Cells. ACS Symp. Ser. 1979, 106, 87-100.

27. Shimizu, M.; Kubo, K.; Morioka, H.; Tani, Y.; Ogata, K., Some Aspects of the Enzyme Activities Involved in Coenzyme A Biosynthesis in Various Microorganisms. Agric. Biol. Chem. 1974, 38, 1015-1021.

28. Shimizu, M.; Kubo, K.; Tani, Y.; Ogata, K., Purification and Properties of Pantothenate Kinase from Brevibacterium ammoniagene IFO 12071. Agric. Biol. Chem. 1973, 37, 2863-2870.

29. Shimizu, M.; Komaki, R.; Tani, Y.; Yamada, H., A High Yield Method for the Preparative Synthesis of Coenzyme A by Combination of Chemical and Enzymic Reactions. FEBS Lett. 1983, 151, 303-306.

30. Stewart, C. J.; Ball, W. J., Coenzyme A analogs. II. Enzymatic conversion of Doxypantetheine 4'-phosphate to oxy-coenzyme A. Biochemistry 1966, 5, 3883-3886.

31. Shimizu, M.; Esumi, A.; Komaki, R.; Yamada, H., Production of Coenzyme A by a Mutant of Brevibacterium ammoniagenes Resistant to Oxypantetheine. Appl. Environ. Microbiol. 1984, 48, 1118-1122.

32. Novelli, G. D.; Schmetz, F. J.; Kaplan, N. O., Enzymatic Degradation and Resynthesis of Coenzyme A. J. Biol. Chem. 1953, 206, 533-545.

33. Levintow, L.; Novelli, G. D., The Synthesis of Coenzyme A from Pantetheine: Preparation and Properties of Pantetheine Kinase. J. Biol. Chem. 1954, 207, 761-765.

34. Baddiley, J.; Thain, E. M., Coenzyme A. Part VIII. The Synthesis of Pantetheine 4'Phosphate (Acetobacter Stirnulatory Factor), a Degradation Product of the Coenzyme. $J$. Chem. Soc. 1953, 1610-1615.

35. Moffatt, J. G.; Khorana, H. G., The Total Synthesis of Coenzyme A. J. Am. Chem. Soc. 1959, 81, 1265-1265.

36. Moffatt, J. G.; Khorana, H. G., Nucleoside Polyphosphates. XII.1 The Total Synthesis of Coenzyme A. J. Am. Chem. Soc. 1961, 83, 663-675.

37. Gruber, W.; Lynen, F., Dinucleotidsynthesen Mit Pyrophosphoryltetrachlorid. Eine Synthese von Coenzym A. Eur. J. Org. Chem. 1962, 659, 139-156.

38. Michelson, A. M., Synthesis of Coenzyme A. Biochim. Biophys. Acta 1964, 93, 71-77.

39. Shimizu, M.; Nagase, O.; Okada, S.; Hosokawa, Y.; Tagawa, H., A Total Synthesis of Coenzyme A via Thiazoline Intermediate. Chem. Pharm. Bull. 1965, 13, 1142-1144.

40. Shimizu, M.; Nagase, O.; Okada, S.; Hosokawa, Y.; Tagawa, H.; Abiko, Y.; Suzuki, T., Investigations on Pantothenic Acid and its Related Compounds.V. Chemical Studies. A total Synthesis of Coenzyme A via Thiazoline Intermediate. Chem. Pharm. Bull. 1967, 15, 655-662.

41. Naoi-Tada, M.; Sato-Asano, K.; Egami, F., Ribonuclease in Taka-Diastase. III. Purification and Properties of Ribonuclease T2. J. Biochem. 1959, 46, 757-764. 
42. Hashimoto, M.; Mukaiyama, T., A Total Synthesis of Coenzyme A by OxidationReduction Condensation. Chem. Lett. 1972, 1, 595-598.

43. Taguchi, Y.; Nishimura, N.; Kakimoto, T.; Mushika, Y., Synthetic Studies on Phosphorylating Reagent. V. A Convenient Synthesis of 2',3'-Cyclic Coenzyme A. Bull. Chem. Soc. Jpn. 1976, 49, 1122-1125.

44. Song, W.-J.; Jackowski, S., Cloning, Sequencing, and Expression of the Pantothenate Kinase (coaA) Gene of Escherichia coli. J. Bacteriol. 1992, 174, 6411-6417.

45. Geerlof, A.; Lewendon, A.; Shaw, W. V., Purification and Characterization of Phosphopantetheine Adenylyltransferase from Escherichia coli. J. Biol. Chem. 1999, 274, $27105-27111$.

46. Mishra, P. K.; Park, P. K.; Drueckhammer, D. G., Identification of yacE (coaE) as the Structural Gene for Dephosphocoenzyme A Kinase in Escherichia coli K-12. J. Bacteriol. 2001, 183, 2774-2778.

47. Billhart, U.; Stein, P.; Whitesides, G. M., Enzymatic Methods for the Preparation of Acetyl-CoA and Analogs. Bioorg. Chem. 1989, 17, 1-12.

48. Martin, D. P.; Bibart, R. T.; Drueckhammer, D. G., Synthesis of Novel Analogs of Acetyl Coenzyme A: Mimics of Enzyme Reaction Intermediates J. Am. Chem. Soc. 1993, 116, 4660-4668.

49. Vogel, K. W.; Drueckhammer, D. G., A Reversed Thioester Analogue of AcetylCoenzyme A: an Inhibitor of Thiolase and a Synthon for other Acyl-CoA Analogues. J. Am. Chem. Soc. 1998, 120, 3275-3283.

50. Bibart, R. T.; Vogel, K. W.; Drueckhammer, D. G., Development of a Second Generation Coenzyme A Analogue Synthon. J. Org. Chem. 1999, 64, 2903-2909.

51. Vogel, K. W.; Stark, L. M.; Mishra, P. K.; Yang, W.; Drueckhammer, D. G., Investigating the Role of the Geminal Dimethyl Groups of Coenzyme A: Synthesis and Studies of a Didemethyl Analogue. Bioorg. Med. Chem. 2000, 8, 2451-2460.

52. Rootman, I.; de Villiers, M.; Brand, L. A.; Strauss, E., Creating CBD-Fusions of the CoA Biosynthetic Enzymes to Enable Reactor-Based Biotransformations. ChemCatChem 2010, 2, 1239-1251.

53. Strauss, E.; Begley, T. P., The Antiobiotic Activity of N-Pentylpantothenamide Results from Its Conversion to Ethyldethia-Coenzyme A, A Coenzyme A Antimetabolite. $J$. Biol. Chem. 2002, 277, 48205-48209.

54. Choudry, A. E.; Mandichak, T. L.; Broskey, J. P.; Egolf, R. W.; Kinsland, C.; Begley, T. P.; Seefeld, M. A.; Ku, T. W.; Brown, J. R.; Zalacain, M.; Ratnam, K., Inhibitors of Pantothenate Kinase: Novel Antibiotics for Staphylococcal Infections. Antimicrob. Agents Chemother. 2003, 47, 2051-2055.

55. Sifferd, R. H.; du Vigneau, V., A New Synthesis of Carnosine, with some Observations on the Splitting of the Benzyl Group from Carbobenzoxy Derivatives and from Benzylthio Ethers. J. Biol. Chem. 1934, 108.

56. Baddiley, J.; Thain, E. M., A new and Convenient Synthesis of Pantetheine (Lactobacillus bulgaricus Factor). J. Chem. Soc. 1952, 800-803.

57. Wittle, E. L.; Moore, J. A.; Stipek, R. W.; Peterson, F. E.; McGlohon, V. M.; Bird, O. D.; Brown, G. M.; Snell, E. E., The Synthesis of Pantetheine-Pantethine. J. Am. Chem. Soc. 1953, 75, 1694-1700.

58. King, T. E.; Stewart, C. J.; Cheldelin, V. H., $\beta$-Aletheine and Pantetheine. J. Am. Chem. Soc. 1953, 75, 1290-1292.

59. Shimizu, M.; Ohta, G.; Nagase, O.; Okada, S.; Hosokawa, Y., A Novel Synthesis of Pantethine. Chem. Pharm. Bull. 1965, 13, 180-188.

60. Mandel, A. L.; La Clair, J. J.; Burkart, M. D., Modular Synthesis of Pantetheine and Phosphopantetheine. Org. Lett. 2004, 6, 4801-4803. 
61. Burkart, A. S.; Laclair, J. Analysis and Manipulation of Enzymes in Biosynthetic Proteomes Using Labeled Carrier Proteins. WO2005003307, 2005.

62. Burkart, A. S.; Worthington, M., D., One-Pot Chemo-Enzymatic Synthesis of Reporter-Modified Proteins. Org. Biomol. Chem. 2006, 4, 44-46.

63. Sewell, A. L.; Villa, V. J.; Matheson, M.; Whittingham, W. G.; Marquez, R., Fast and Flexible Synthesis of Pantothenic Acid and CJ-15,801. Org. Lett. 2011, 13, 800-803.

64. Kandula, M. Compositions and Methods for the Treatment of Inflamation and Lipid Disorder. WO2014037834 2014.

65. Mouterde, L. M. M.; Stewart, J. D., An Efficient Chemoenzymatic Synthesis of Coenzyme A and Its Disulfide. Org. Process Res. Dev. 2016, 20, 954-959.

66. Agarwal, V.; Diethelm, S.; Ray, L.; Garg, N.; Awakawa, T.; Dorrestein, P. C.; Moore, B. S., Chemoenzymatic Synthesis of Acyl Coenzyme A Substrates Enables in Situ Labeling of Small Molecules and Proteins. Org. Lett. 2015, 17, 4452-4455. 